\title{
AS LETRAS DE UMA REVOLUÇÃO: A IMPLANTAÇÃO DA REPÚBLICA EM PORTUGAL A 5 DE OUTUBRO DE 1910
}

\author{
The letters of a Revolution: the implantation of \\ the Republic in Portugal on October 5, 1910
}

Las letras de una Revolución: el establecimiento de la República en Portugal el 5 de octubre 1910

ANA PAULA PIRES

Ana Paula Pires é doutora em História, com especialidade em História Económica e Social Contemporânea, pela Universidade Nova de Lisboa, Portugal. É membro da direção do Instituto de História Contemporânea da Faculdade de Ciências Sociais e Humanas da Universidade Nova de Lisboa e coordenadora do grupo de investigação "Economia, Sociedade, Património e Inovação". É atualmente visiting scholar na Universidade de Stanford (asoarespires@gmail.com).

Artigo recebido em 1 de fevereiro e aprovado para publicação em 8 de maio de 2017. 


\section{RESUMO}

A implantação da República portuguesa em 5 de outubro de 1910 culminou um processo que remonta ao final do século XIX e, em especial, aos seus últimos anos. Trata-se de um período de condensação de um contexto de crise multifacetada em que se inscreveu o colapso da Monarquia constitucional e o rasgo de um caminho, de certa forma inexorável, que conduziu à República. 0 texto analisa a preparação da Revolução e a implantação da República em Portugal.

Palavras-CHAVE: republicanismo; revolução; Portugal; monarquia; Partido Republicano Português; Brasil.

\section{AbSTRACT}

The proclamation of the Republic in Portugal on October 5th 1910 closed a process that began at the end of the XIXth century, especially in its later years. The period is characterized by a condensation of a multifaceted context of crisis in which were inscribed the collapse of the constitutional Monarchy and the opening of an inexorable path leading to the Republic. This paper analyses the preparation of the revolution and the proclamation of the new regime in Portugal.

KeYwORDs: republicanism; revolution; Portugal; monarchy; Portuguese Republican Party; Brazil.

\section{RESUMEN}

La implantación de la República Portuguesa el 5 de octubre de 1910 culminó un proceso que se remonta a finales del siglo XIX y, en particular, a sus últimos años; fue un período de condensación de un contexto de crisis multifacética que ha registrado el colapso de la monarquía constitucional y la abertura de un camino, de cierta forma inexorable, que llevó a la República. El texto analiza la preparación de la Revolución y el establecimiento de la República en Portugal.

Palabras Clave: republicanismo; revolución; Portugal; monarquía; Partido Republicano Portugués; Brasil. 
A proclamação da República foi apenas a condição para se adoptarem processos mais justos, mais racionais, de maior valor que os da Monarquia, mas foi apenas isso, e não uma varinha mágica, como nos contos de fadas, capaz de improvisar maravilhas de toda a ordem.

(Brito Camacho, 1920: 73-74)

\section{A IDADE DA INOCÊNCIA}

República portuguesa foi implantada há precisamente 107 anos. Em 2010, por ocasião
da passagem do seu primeiro centenário, foi constituída uma Comissão Nacional para as Comemorações do Centenário da República, cuja missão foi preparar, organizar e coordenar um programa comemorativo que decorreu entre 31 de janeiro de 2010 e agosto de 2011, data em que se assinalou o centenário da primeira Constituição republicana. 0 Programa deste Centenário incluiu mais de 500 manifestações culturais, colóquios, edições, jogos desportivos, espectáculos e concursos realizados um pouco por todo o país ${ }^{1}$ e procurou contribuir para o desenvolvimento da investigação e do estudo de algumas temáticas fundamentais para a compreensão da história da I República e do Republicanismo, como o desenvolvimento do ensino e da investigação científica (Salgueiro, 2015) ou a análise do sistema partidário e do sistema eleitoral (Leal, 2014). Apesar de grande parte destes trabalhos terem tido como principal enfoque a natureza política do regime, nomeadamente a sua natureza instável (45 governos ao longo de 16 anos de duração) (Sousa, Ramos e Monteiro, 2012), a análise do momento da preparação da Revolução e da implantação da República acabou por surgir enquadrada em análises mais gerais de que fazem parte a obra coordenada por Fernando Rosas e Fernanda Rollo (2009), o estudo de Alice Samara (2010), cujo objectivo foi analisar a Primeira República enquanto construção na óptica da cultura política do republicanismo, ou ainda, mais recentemente, o trabalho de Isabel Corrêa da Silva (2013), autora de um estudo comparativo do movimento republicano em Portugal e no Brasil, com particular enfoque na comunidade portuguesa residente no Rio de Janeiro.

0 texto que agora se apresenta procura assim preencher uma lacuna existente na historiografia portuguesa e brasileira ao analisar de forma detalhada a preparação da revolução e a implantação da República em Portugal a 5 de outubro de 1910, investigando as ações 
levadas a cabo pelo Partido Republicano Português tendo em vista o derrube da Monarquia Constitucional e enquadrando-as no contexto económico e social do país. 0 artigo parte por isso da análise de artigos publicados na imprensa, na sua maioria inéditos, memórias e ensaios, bem como do estudo dos discursos proferidos pelos republicanos na Câmara dos Deputados antes da proclamação da República.

A implantação da República portuguesa culminou um processo que remonta ao final do século XIX e, em especial, aos seus últimos anos; período de condensação de um contexto de crise multifacetada em que se inscreveu o colapso do regime monárquico e o início de um percurso que conduziu à República. Importa assim mencionar os acontecimentos em torno do Ultimato britânico (janeiro de 1890), a onda de agitação que provocou e as sequelas que desencadeou, nomeadamente a revolta republicana do Porto a 31 de janeiro de 1891.

A ideia de crise e decadência que intelectuais como Guerra Junqueiro, Eça de Queiroz ou António Nobre denunciaram implacavelmente através da escrita encerrava uma imagem cujos contornos iam muito além do mero interesse político, denunciando o próprio esgotamento do modelo económico da Regeneração, e expondo as dificuldades financeiras crescentes que Ihe estavam subjacentes, em particular o trauma e a ameaça constante da bancarrota que a partir de 1890/91 assolaram o país.

Em 1871 o grupo do Cenáculo, impulsionado sobretudo por Antero de Quental e Jaime Batalha Reis, tinha organizado as célebres Conferências Democráticas do Casino Lisbonense (Reis, 1990), verdadeiro areópago da intelectualidade lusa onde se avançaram algumas explicações para o atraso português e espanhol - síntese que Antero de Quental se encarregou, de resto, de elaborar (Quental, 1994) -, se discutiram e foram postas em confronto duas formas de governo: monarquia/república. A revolução, entendida como ciência, era apresentada como o caminho a seguir, tal como, de resto, o próprio Eça de Queiroz tinha já apontado (Mónica, 2001: 1013-1014).

0 contexto era propício a que se criticasse abertamente as opções seguidas pela Monarquia, votando-se ao descrédito a (in)ação do monarca, o rei D. Carlos (Pires, 2011). 0 divórcio entre a Monarquia e a Nação era cada vez mais visível, tornando oportuna uma mudança de regime que os republicanos protagonizariam, entusiasmados com o exemplo recente da proclamação da República brasileira, a 15 de novembro de 1889.

Portugal buscava o seu ressurgimento económico e financeiro, confrontado com as expectativas falhadas e sob o trauma e a ameaça da bancarrota. É certo, porém, que o período que antecedeu a Primeira Guerra Mundial registou um crescimento razoável do sector industrial, tal como aconteceu com a maioria das economias europeias mais atrasadas, mas circunscrito e longe de conseguir catapultar Portugal para o nível dos países industrializados da Europa. 


\section{Crescimento económico em Portugal, 1890-1910}

(taxas do crescimento anual, em percentagem)

\begin{tabular}{|llllll} 
Anos & PIB per capita & Agricultura & Indústria & Serviços & PIB \\
\hline 1890-1900 & 0,98 & 1,58 & 3,00 & 0,68 & 1,59 \\
\hline 1900-1910 & 0,42 & 0,03 & 2,16 & 2,06 & 1,29 \\
\hline Fonte: Lains, 2003: 165. & & & &
\end{tabular}

Globalmente, o País falhou em encetar um processo de industrialização e modernização económica e social, mantendo taxas de crescimento muitíssimo modestas. A verdade é que os vários governos da fase final da Monarquia, a braços com sucessivas crises políticas e financeiras, estavam praticamente paralisados: não tinham condições, nem meios, para definir uma estratégia de desenvolvimento económico nacional, nem conseguiam reunir os meios indispensáveis à sua concretização. A tudo isso somavam-se os efeitos da indefinição quanto ao percurso que devia presidir à condução dos destinos do desenvolvimento económico do País, e ampliava-se o debate que opunha, em termos de ideias, duas concepções contraditórias, que defendiam caminhos diferentes, assentes na promoção da industrialização ou na primazia do quadro agrícola.

A difícil situação financeira em que o modelo económico de Fontes Pereira de Melo tinha deixado o País agravou-se num cenário de crise a que não foi estranha a situação internacional e, em particular, a crise cambial brasileira e a decorrente contracção das remessas dos emigrantes $^{3}$ que permitiam compensar, significativamente, o quadro tradicionalmente deficitário das trocas portuguesas e, assim, ajudar a compor a situação financeira do País.

\section{Emigração}

Milhares de habitantes

\begin{tabular}{lll}
\hline 1890 & 1900 & 1910 \\
\hline 20,6 & 21,2 & 39,5 \\
\hline
\end{tabular}

Em maio de 1891 foi decretada a suspensão da convertibilidade da moeda, a que, em breve, em junho, se seguiu o abandono do padrão-ouro. Falou-se de bancarrota e o público reagiu em pânico: entre maio e setembro de 1891 acorreu aos depósitos bancários e à conversão de notas. 0 Banco de Portugal ficou sem reservas e outros bancos acabaram por suspender pagamentos.

O século XX surgia assim num contexto de crise política a que se associou, logo, uma profunda crise económica e financeira, que colocaria um ponto final ao liberalismo português. 
As tentativas de regeneração do regime monárquico, as humilhações externas e, sobretudo, a bancarrota do Estado constituíam o prenúncio da queda inexorável do regime.

A 15 de novembro de 1889 um grupo de militares sob a liderança do marechal Deodoro da Fonseca tinha deposto, no Rio de Janeiro, o Imperador D. Pedro II, proclamando a República no Brasil (Barbosa, 2002). A notícia começou por circular de forma bastante restrita em Portugal, alcançando essencialmente as camadas mais bem informadas da população portuguesa, sobretudo aquelas que frequentavam os clubes. Os republicanos receberam-na com entusiasmo. ${ }^{4}$ Nas páginas de 0 Século, Latino Coelho ${ }^{5}$ lembrava que o Brasil era a última monarquia do continente americano, o que, em seu entender, justificava por si só, naturalmente, a República recém-implantada. ${ }^{6}$

Em Coimbra a proclamação da República brasileira não passou despercebida aos olhos dos estudantes republicanos que frequentavam a Universidade. Nas páginas da imprensa surgiram vários artigos em que se teceram críticas à Monarquia, enaltecendo-se as virtudes da jovem República do Brasil. ${ }^{7}$ António José de Almeida, ${ }^{8}$ que então frequentava o $1{ }^{\circ}$ ano do curso de Medicina, participou mesmo num banquete comemorativo da implantação da República no Brasil organizado pelos republicanos de Coimbra. ${ }^{9}$

A imprensa republicana floresceu ao longo destes anos, beneficiando de todo este clima de descontentamento. Na Escola Médico-Cirúrgica de Lisboa, por impulso do então finalista de Medicina Higino de Sousa, ${ }^{10}$ fundou-se em 1890 o jornal A Pátria, cujos artigos doutrinários, assinados maioritariamente por antigos alunos da Escola, tiveram um grande impacto junto da juventude académica. José Estevão de Vasconcelos, Afonso Henriques do Prado Castro Lemos e Manuel de Brito Camacho ${ }^{11}$ contavam-se entre os seus colaboradores.

A 12 de janeiro de 1891 era publicado o Manifesto do Partido Republicano Portuguez, primeiro documento programático do PRP, e o seu tom era já marcadamente revolucionário, reflexo das discussões que tinham tido lugar no último congresso do partido. ${ }^{12}$ De ressalvar, todavia, o facto, de resto notório, do documento conter, quanto ao essencial, preocupações de cariz político, relacionadas com a organização dos poderes do Estado e o estabelecimento das liberdades essenciais, políticas e civis (Samara, 2009: 64-65). Assinale-se que no mesmo dia era constituído no Porto, com cento e cinquenta associados, o Centro Democrático Federal 15 de Novembro (Barbosa, 2002: 107).

No último dia do mês eclodia no Porto a primeira revolta armada contra a Monarquia. ${ }^{13} \mathrm{~A}$ revolta teve 0 apoio de alguns militares e de muitos populares. Mas a guarda municipal, fiel à Monarquia, venceu os revoltosos. 0 número de mortos foi grande. Os revoltosos que não conseguiram fugir foram presos e julgados em tribunais militares reunidos em navios de guerra fundeados em Leixões. 
É impossível ignorar o peso significativo que o 31 de janeiro teve no fortalecimento de uma corrente no interior do PRP, para quem tomada de poder e revolução eram conceitos indissociáveis, ainda que num primeiro momento se tivesse verificado um certo recuo de posições. 0 momento essencial na história do movimento republicano antes da implantação da República foi uma derrota: para o jornal 0 Mundo, "uma revolução que ainda não acabou", 14 contudo, para os revolucionários que estariam envolvidos no 5 de Outubro, a sua verdadeira escola seria a conspiração de 28 de janeiro de 1908 (Samara, 2010: 19).

\section{Do Regicídio Ao Fim da MONARQuia}

28 de janeiro de 1908 republicanos e dissidentes do Partido Progressista, sob o co-
mando da Carbonária Portuguesa, ${ }^{15}$ prepararam uma intentona cujo principal alvo era o Presidente do Conselho de Ministros, João Franco. A conspiração acabou por estar na origem não só da prisão, dias antes, de João Chagas, França Borges, Luz de Almeida, António José de Almeida, Álvaro Poppe, Ribeira Brava, Afonso Costa e Egas Moniz (os dois últimos no célebre episódio do elevador da biblioteca), mas também da emissão de mandatos de captura contra José de Alpoim, João Pinto dos Santos e os viscondes de Pedralva e do Ameal (Magalhães, 2009:143-145). A 31 de janeiro D. Carlos assinava um decreto condenando os revoltosos ao degredo: ${ }^{16}$ com ele, promulgou também a sua sentença de morte. A 1 de fevereiro de 1908 o rei D. Carlos foi assassinado juntamente com o seu filho, o príncipe herdeiro, D. Luís Filipe, em pleno coração de Lisboa.

Era preciso agora gerir posições e consolidar equilíbrios, dentro e fora do PRP, sobretudo porque, para além dos principais líderes do partido, Afonso Costa, António José de Almeida e João Chagas, se encontrarem presos, era claramente contranatura que a mudança de regime se fizesse sobre a morte do rei e do príncipe. Havia, antes de mais, que dissociar o PRP, ou pelo menos os seus principais líderes, de qualquer tipo de envolvimento direto no regicídio (Camacho, 1920:109-110). ${ }^{17}$

Iniciou-se então no estrangeiro uma campanha intensa de propaganda e de habilitação da República e dos seus valores, reação rápida e perspicaz dos dirigentes republicanos ao teor das notícias que, um pouco por todo o mundo, iam sendo publicadas nas páginas da imprensa, dando conta do regicídio. ${ }^{18}$ Ao choque e à consternação que encimavam manchetes, respondeu António José de Almeida com uma entrevista publicada no jornal parisiense Le Matin, logo a 17 de fevereiro de 1908, onde clarificou posições e deixou claro que a queda de João Franco e a morte do rei em nada impediriam o avanço da República, uma vez que esta era uma aspiração essencialmente popular. 
A 1 de novembro o Partido Republicano venceu as eleições em Lisboa e em mais 16 municípios. ${ }^{19}$ Lisboa tornava-se assim uma das primeiras capitais republicanas da Europa. ${ }^{20}$ De resto, esta vitória emblemática e representativa acabou por estar na origem, não só do pedido de demissão apresentado pelo primeiro-ministro, Ferreira do Amaral, a 25 de dezembro, mas também da credibilização, dentro do PRP, da linha ordeira que no seu interior vinha defendendo uma vitória da República e do republicanismo, sem recurso a violências ou atos revolucionários.

Na verdade, seria só no Congresso Republicano de Setúbal, realizado nos dias 23 a 25 de abril de 1909, no Teatro D. Amélia, por entre discussões acaloradas, que a via revolucionária sairia vencedora em toda a linha. À luz do que se perspectivava, e tendo por base uma proposta de João Chagas, foram constituídos dois comités revolucionários: um civil e um militar. Logo após o encontro, António José de Almeida, por indicação expressa da Alta Venda da Carbonária, ficou encarregue de chefiar a "direcção" civil, cabendo a Cândido dos Reis, João Chagas e Afonso Costa dirigir a facção militar. Assinale-se que ambos os comités deveriam funcionar em articulação com os grupos que a Carbonária vinha já organizando, nos quartéis e nos bairros populares.

\section{ReVoluÇÃo}

o final de abril de 1910 (dias 29 e 30), os republicanos reuniam em congresso, na
cidade do Porto. Um dos aspectos mais visíveis do encontro foi, justamente, o receio de que a Inglaterra não reconhecesse a República portuguesa, caso esta fosse implantada, obrigando a que se definisse, com celeridade, uma alternativa. 0 desfecho culminaria na decisão de enviar ao estrangeiro uma missão representativa do PRP, tendo o directório definido prontamente a sua constituição, escolhendo para a integrar quatro nomes emblemáticos do partido: Bernardino Machado, José Relvas, Sebastião de Magalhães Lima e Augusto Alves da Veiga (Santos, 1979: 27). Impossibilitado de integrar a missão, por motivos de natureza pessoal, Bernardino Machado não chegou a acompanhar José Relvas, que partiu sozinho de Lisboa, uma vez que tanto Magalhães Lima como Alves da Veiga já se encontravam em Paris. ${ }^{21}$

António José de Almeida sabia a importância de que o assunto se revestia e deixou o seu apoio à direcção do PRP gravado, de forma expressiva, num artigo de fundo que fez publicar nas páginas da recém-lançada revista Alma Nacional: "O Congresso, pois, fez bem em mandar ao estrangeiro uma missão, que esclarecendo os centros principais da política europeia, sobre as nossas crises internas, lhes notificasse a razão que assiste, sob todos os aspectos, ao povo português, no seu legítimo anseio revolucionário". ${ }^{22}$ A observação foi, 
imediatamente, completada pela constatação da inevitabilidade da internacionalização: "(...) todo o mundo sabe que, para um povo ter uma vida superior e autónoma, precisa de respirar uma atmosfera internacional de prestígio e respeito" ${ }^{23}$

De resto, são particularmente interessantes e elucidativas as palavras que referiu também a respeito da necessidade de se efectuarem contactos e estreitarem relações com o Brasil: "Outra missão é preciso expedir sem demora, não para o estrangeiro, mas para o Brasil. Permitam-me que eu me explique assim. 0 Brasil, para nós portugueses, embora sendo uma nação alheia, não é uma nação estranha. Ele não é o estrangeiro, ele é afinal uma Pátria irmã (...) Pois o Brasil, em contacto permanente connosco, está mal elucidado sobre as dificuldades sombrias que pesam, no actual momento, sobre Portugal, e o que é mais desconsolador, a colónia portuguesa, e especialmente a do Rio de Janeiro, tanto desconhece a sua vida política que, na generalidade ao menos, nos dedica a nós, republicanos, um ódio enraivado e sem quartel". ${ }^{24}$ Em síntese, António José de Almeida mostrava que "se a opinião favorável da Europa nos é útil para a transformação das instituições do nosso País, e, depois, para o preenchimento da nossa missão histórica, a simpatia do Brasil (...) é-nos indispensável" 25

O Partido Republicano levaria a cabo ainda uma estratégia de combate às políticas do Governo na Câmara dos Deputados. O Parlamento tinha reaberto no início de março e Afonso Costa, a propósito do pedido de renovação - por mais quinze anos - do monopólio da compra de açúcar na ilha Madeira pela firma britânica Hinton \& Sons, aproveitou para denunciar, logo no mês seguinte, os negócios menos lícitos envolvendo Harry Hinton e o ajudante de campo de D. Manuel II, Fernando de Serpa Pimentel, deixando enunciada a prática de subornos a políticos influentes. ${ }^{26}$

A "descoberta" veio evidenciar o agravamento da situação política, tendo impactos imediatos: D. Manuel, após ouvir o Conselho de Estado, acabou por ordenar o encerramento do Parlamento, até 1 de junho. A atitude surpreendeu poucos, dignos de registo são os comentários de António José de Almeida, chamando a atenção, um pouco antes da polémica ter chegado ao Parlamento, para a pressão que o governo britânico iria exercer sobre Portugal caso as imposições da firma Hinton não fossem satisfeitas. Em fundo pairava também a ameaça de deixar de comprar cana-de-açúcar na Madeira feita pela firma britânica, e que, a cumprir-se, arruinaria os produtores do arquipélago: "(...) a Inglaterra não terá o mínimo rebuço em bater o pé, - aquele forte e brutal pé britânico -, ao governo português, se ele não satisfizer de pronto, ao aventureiro Hinton, as exigências monetárias que ele nos fez. Ela procederá, no lance, em harmonia com o seu passado e segundo os rigores da sua fé púnica, e nós não temos direito a queixar-nos, porque há muito sabemos que a formidável nação 
mede a sua ânsia de justiça pela sua febre de lucro, e quando as suas chancelarias não têm a lógica suficientemente cerrada para sustentar as suas intimativas, a goela dos seus canhões é que se encarrega de impor silêncio ao espoliado que se queixa". ${ }^{27}$ Depois dessa apreciação mais geral reafirmou o que considerava dever ser o papel e a atitude do Partido Republicano Português: "(...) perturbar, agitar, complicar, abalar, derruir. (...) por forma a (...) caminhar para o poder por entre os escombros do regime desconjuntado". ${ }^{28}$

No início do mês seguinte - a 1 de maio - foram reveladas novas irregularidades, envolvendo desta feita a Companhia Geral do Crédito Predial (CGCP), o líder do Partido Progressista, José Luciano de Castro, à data seu governador, e o ministro da Justiça, Artur Montenegro, membro do conselho fiscal (Sousa, 1912:101). Augusto Pedro de Oliveira Quintela, guarda-livros da CGCP, tinha falsificado as contas do banco, deixando-o à beira da falência. Em 1910, quando o caso veio a público, só um empréstimo do Banco de Portugal seria capaz de resolver o problema.

Veja-se a complexidade do assunto, tendo presente o apreciável elenco de personalidades que se lhe encontravam associadas, o que acabou por levar D. Manuel II a recomendar a José Luciano de Castro, ainda antes de rumar à Inglaterra para assistir ao funeral de Eduardo VII, que fizesse uso da sua influência para tentar um acordo entre partidos, de modo a evitar uma crise política.

Claro que os contornos e a complexidade desta polémica não escaparam aos republicanos nem passaram despercebidos, uma vez mais, a António José de Almeida, que os seguiu atentamente, não se imiscuindo de tecer duras críticas ao líder político dos Progressistas: "Tem perturbado pela violência, tem perturbado pela intriga, tem perturbado pela corrupção. Cem vezes a sua mão teve ensejo de fazer um gesto de apaziguamento, e, todavia, ela só desferiu incitamentos à perseguição. Cem vezes a sua boca podia ter soltado uma palavra de justiça ou bondade, e, todavia ela só rugiu ameaças e sentenças condenatórias. Cem vezes a sua aç̧ão podia ter sido moralizadora e edificativa, e, todavia, ela só contribuiu, em lances sucessivos, para mais alargar o seu vasto pântano onde a sociedade portuguesa se revolve como um credo na vaza imunda". ${ }^{29}$ Refira-se em que medida o caso Crédito Predial vinha precisamente condensar expectativas e promover o debate em torno das desuniões e da estratégia a prosseguir pelos republicanos.

A 15 de maio, cerca de cinco mil pessoas assistiram ao comício organizado pelo PRP na Cova da Piedade, a sul de Lisboa. Outras tantas multiplicavam-se em acções de propaganda na Aldeia Galega, Alcochete, Seixal e Almada. O PRP contabilizava apoios ao Sul do Tejo, a sua população, apesar do pouco significado que tinham as bandeiras "Liberdade", "Igualdade" e "Fraternidade" apregoadas pelos republicanos, agitava-se, contagiada pelas perspectivas 
de mudança que a propaganda deixava cair, adivinhando-se expectativas de graus diferentes quanto à possível melhoria das condições de vida.

A notícia da demissão do Governo chegou a 22 de junho. 0 acontecimento teve, como não podia deixar de ser, repercussões importantes de diversa natureza, a começar, desde logo, pelo encerramento, por decisão do Conselho de Estado, da Câmara dos Deputados e pela marcação de eleições para 28 de agosto. Seja como for, em termos políticos as coisas acabaram por não melhorar; o coro de protestos foi alastrando, e as críticas dirigidas a Teixeira de Sousa, subindo progressivamente de tom, denunciavam o seu liberalismo excessivo e a proximidade que mantinha de republicanos e dissidentes. A breve trecho, formar-se-ia um bloco reunindo as mais diversas facções do espectro monárquico: progressistas, henriquistas, franquistas, nacionalistas e católicos (Almeida, 2004:147). Todos juntos planeavam o derrube do Governo, mas, como facilmente se depreende, estavam longe de compor um grupo coeso e uniforme.

Foi a partir daqui que os conteúdos (ou a sua ausência) e a estrutura que enformavam o programa político do PRP começaram a despertar, ainda que de forma velada, algum cuidado e interesse. A questão foi abordada frontalmente pelo republicano António José de Almeida, um dia após a tomada de posse do novo Governo: "Pois é preciso apontar de maneira clara, terminantemente e leal o nosso programa. Nós o temos há muito, como é sabido; mas urge modificá-lo nalguns pontos onde disso precise, mesmo que ele seja, como ninguém ignora, um dos mais completos, avançados e perfeitos programas de reivindicação que existe na Europa. $E$ depois de modificado, é indispensável desenvolvê-lo, comentá-lo e demonstrá-lo, de maneira a que as suas verdades se imponham a todas as consciências sãs e entrem em todos os espíritos honestos" ${ }^{30}$ Na verdade, o assunto era muito importante, sobretudo se tivermos presente que o programa político do PRP não era alterado há praticamente uma década, conservando, quanto ao essencial, traços de um programa de protesto e não de um plano de governo.

Não é portanto surpreendente que António José de Almeida tenha registado algumas das críticas mais recorrentes apontadas pelos monárquicos e que, na sua maioria, entroncavam na ausência de um projecto de governação por parte dos republicanos: "Nós, bradam eles, não preleccionamos as vantagens teóricas do regime republicano sobre o monárquico, e muito menos pomos, perante os olhos das massas, a solução concreta que nos propomos dar aos problemas capitais da nossa vida económica e social. Prometemos, (. . .) o bacalhau a três vinténs, mas não dizemos que espécie de regalias ou vantagens daremos, com a república, à grande massa dos trabalhadores; como havemos de extinguir o deficit que pesa, como uma montanha de bronze, sobre as finanças da nação; onde havemos de ir buscar dinheiro para realizar toda essa longa lista de melhoramentos (...) que o país irremediavelmente carece". ${ }^{31}$ Na verdade, um dos aspectos mais visíveis da propaganda republicana continuava 
a prender-se/circunscrever-se à separação do Estado das igrejas. António José de Almeida apontou-o, também: "Tem-se dito milhares de vezes que no programa do partido republicano existe, nítida e desassombradamente, o princípio da separação da igreja e do Estado. Pois é preciso dizer agora, com a sanção oficial do partido quais são os termos, tanto quanto possível detalhados, em que essa separação há-de ser feita". ${ }^{32}$

Na verdade, uma vez conquistado o poder, era preciso estruturar o regime; cimentá-lo, apoiando-o num projecto geral que não se circunscrevesse apenas à questão política/religiosa, mas que se concentrasse na elaboração de uma estratégia, duradoura e coerente; que passasse pela criação, e desenvolvimento, de fontes de riqueza, base indispensável da unidade e transformação nacional que se pretendia alcançar e neste domínio a República iria falhar.

Por esta altura Machado Santos ${ }^{33}$ vinha estabelecendo contactos com o Grande Oriente Lusitano (GOL), o Supremo Conselho da Maçonaria portuguesa. O GOL reuniu em assembleia-geral a 14 de julho de 1910: durante o encontro foi nomeada uma Comissão de Resistência Maçónica (CRM), presidida pelo vice-grão mestre da maçonaria José de Castro, e que integrava nomes como Simões Raposo, Cordeiro Júnior, Francisco Grandela e Manuel Barbosa. Foi também desse encontro de julho de 1910 que resultou a escolha de António José de Almeida para integrar a CRM na qualidade de "civil", todavia António José acabou por ser substituído pouco tempo depois, a seu pedido, por António Maria da Silva.

A campanha eleitoral foi animada pelo tom agressivo com que nos jornais, revistas e panfletos, se dirigiram ataques a Teixeira de Sousa, a D. Manuel e a D. Amélia, sua mãe. Assinale-se, a propósito, o tom profundo com que, uma vez mais nas páginas de Alma Nacional, António José de Almeida falou da importância da oratória, sublinhando a necessidade de se escolherem adequadamente os oradores para darem corpo aos valores e ao ideário do PRP: "Não é só ir pregar a boa doutrina aos pontos em que essa pregação se torna precisa. É necessário escolher os oradores em harmonia com os meios em que têm de falar. Lisboa, Porto, Coimbra, Beja, etc., onde a convicção republicana ou a simpatia pela república são um facto, exigem oradores iconoclastas, ardentes e vingadores, cuja missão se traduza em incendiar os espíritos há muito preparados para essa combustão patriótica. Os meios religiosos onde os espíritos se conservam imersos na noite clerical, como a Guarda ou a Covilhã, exigem oradores de palavra suasória e calma, aptos a lançar nas almas desconfiadas, com naturalidade e brandura, o fermento da insurreição" ${ }^{34}$ A luta nas urnas era vista como o prólogo do combate nas ruas. Ao assumir esta postura Almeida mostrava-se empenhado na união dos republicanos, procurando anular, pelo menos temporariamente, as diferenças de posição que se iam divisando de forma cada vez mais notória no seio do PRP, revelando uma boa percepção das circunstâncias que no momento envolviam politicamente o País. 
Os republicanos tiveram nas eleições de 28 de agosto de 1910 o seu melhor resultado de sempre, conseguindo eleger 14 deputados, 10 dos quais pelo círculo de Lisboa. ${ }^{35} 0$ governo elegeu 89, conseguindo a maioria na Câmara dos Deputados, apesar do acto eleitoral não ter sido validado em 9 dos 26 círculos em que o País se dividia.

\section{Evolução do número de deputados eleitos pelo PRP}

\begin{tabular}{|llll}
\hline Data do acto eleitoral & Número de deputados eleitos & Círculo \\
\hline 13 de outubro de 1878 & 1 & Porto \\
\hline 19 de outubro de 1879 & 1 & Porto \\
\hline 21 de agosto de 1881 & 2 & Lisboa \\
\hline 29 de junho de 1884 & 2 & Lisboa \\
\hline 6 de março de 1887 & 2 & Lisboa \\
\hline 20 de outubro de 1889 & 2 & Lisboa (1) \\
\hline 30 de março de 1890 & 4 & Porto (1) \\
\hline 23 de outubro de 1892 & 3 & Lisboa (3) \\
15 de abril de 1894 & 2 & Acumulação (1) \\
\hline 17 de novembro de 1895 & - & Lisboa (2) \\
\hline 2 de maio de 1897 & - & Porto (1) \\
\hline 26 de novembro de 1899 & 3 & Lisboa \\
\hline 25 de novembro de 1900 & - & - \\
\hline 6 de outubro de 1901 & - & - \\
\hline 26 de junho de 1904 & - & Porto \\
\hline 12 de fevereiro de 1905 & - & - \\
\hline 29 de abril de 1906 & 1 & - \\
\hline 19 de agosto de 1906 & 4 & - \\
\hline 5 de abril de 1908 & & Beja (1) \\
\hline 28 de agosto de 1910 & & Setúbal (2) \\
\hline & & - \\
\hline
\end{tabular}

Fonte: Proença (2008: 35-36).

0 Parlamento foi aberto de forma solene a 23 de setembro, encerrando dois dias mais tarde. ${ }^{36} \mathrm{Na}$ véspera, António José de Almeida tinha-se despedido dos seus leitores de a Alma Nacional, de forma clara e sucinta: "O partido republicano chegou à maioridade e seria ridículo estar a pregar-lhe conselhos" ${ }^{37}$ 
As Cortes não mais voltariam a reunir, em Portugal.

No início de outubro de 1910, poucas dúvidas restavam de que o País estava à beira de assumir um processo de mudança cujo fim seria inevitavelmente a implantação da República. Sintomaticamente duas das principais figuras do Partido Republicano Português, Magalhães Lima e Afonso Costa, em entrevistas concedidas meses antes aos jornais Daily News e Le Matin haviam já deixado no ar a certeza de que "grandes acontecimentos se produziriam em breve em Portugal".

Sob a pressão decisiva da Carbonária e com o apoio da ala do Partido Republicano Português defensora do recurso às armas, os republicanos lançaram-se finalmente, após dois anos de controvérsias e hesitações, ao assalto do poder em Lisboa. 0 Directório do Partido contava por esta altura com o apoio da quase totalidade da guarnição militar de Lisboa.

A 3 de outubro, logo pela manhã, as páginas dos principais jornais lisboetas noticiavam o assassínio do psiquiatra republicano e presidente da Liga Liberal, Miguel Bombarda. ${ }^{38} 0$ Diretor do Hospital de Rilhafoles não conseguira sobreviver às quatro balas desferidas por Aparício Rebelo dos Santos, seu antigo doente. Brito Camacho esteve a 3 de outubro de 1910 no Hospital de S. José, nos momentos finais da vida de Miguel Bombarda: foi a Camacho que Bombarda confiou as últimas indicações para a preparação da revolta, solicitando-Ihe igualmente a destruição de vários documentos que temia poderem tornar-se comprometedores, acabando mesmo por lhe confessar não valer "a pena conservar a vida por aquele preço". ${ }^{39}$ No regresso à redação do jornal que dirigia - A Lucta - Camacho escreveu que a morte do diretor de Rilhafoles "marcava o início de um estado revolucionário que iria conduzir à solução da crise que perturbava a Nação" ${ }^{40}$ Ao longo de toda a noite e durante o dia seguinte, redigiu proclamações revolucionárias apesar de temer o desânimo e o impacto negativo que a morte de Bombarda poderia gerar junto dos revolucionários. Anos mais tarde, Camacho confessou pretender apenas, caso o movimento revolucionário não vingasse, reduzi-lo "a uma ligeira tentativa de perturbação da ordem pública em Lisboa", ${ }^{41}$ sem, no entanto, nunca relegar o papel e a importância do jornal que dirigia no triunfo do movimento republicano de 5 de outubro de 1910: "Da redação partiram as ordens para ser retida, se fosse preciso, artilharia 3 que marchava sobre Lisboa; dali partiram indicações com respeito a infantaria 15, que vinha em comboio (...) dali partiu o aviso de que a polícia recebera ordem para ir armar-se ao regimento de artilharia, e também dali partiu o aviso da marcha de Couceiro (...) Ali se forjaram proclamações, que muito serviram para levantar os ânimos, e ali estiveram membros do Diretório (...) saí do meu posto quando já estava vencida a monarquia, - e à hora em que nos Paços do Conselho se proclamava o Governo Provisório e se recebiam abraços e felicitações (...)". ${ }^{42}$ 
O Presidente do Conselho de Ministros, Teixeira de Sousa, temendo que o assassínio de Miguel Bombarda provocasse distúrbios na capital, deu ordem para que todas as unidades da guarnição de Lisboa ficassem de prevenção.

0 movimento revolucionário iniciou-se na madrugada do dia 4 de outubro quando 0 Comissário Naval Machado Santos, acompanhado de alguns civis, partiu do Centro Republicano de Santa Isabel em direção ao Quartel de Infantaria 16, dando vivas à República (Santos, 1982: 70). Cândido dos Reis suicidou-se nessa mesma madrugada; o almirante, temendo que a revolução estivesse perdida, pôs termo à vida com um tiro de revólver. Os republicanos tentaram a todo o custo abafar a notícia, receando que a sua repercussão acabasse por frustrar a revolta em curso.

No Palácio de Belém D. Manuel II jantava com o presidente eleito do Brasil, Hermes da Fonseca, que dias antes tinha chegado a Lisboa, a bordo do couraçado S. Paulo. A 4 de outubro de 1910, depois de jantar com o presidente do Brasil, o rei, D. Manuel II, partiu para o Palácio das Necessidades, enquanto o seu tio, e herdeiro da coroa, D. Afonso, seguia para a Cidadela de Cascais. ${ }^{43}$

0 movimento revolucionário partiu de pequenos grupos de conspiradores - membros do Exército e da Marinha (oficiais e sargentos), alguns dirigentes civis e grande número de populares armados. A revolução apoiava-se na revolta dos principais quartéis de marinheiros da capital (o Quartel de Marinheiros em Alcântara e o Arsenal de Marinha, à Praça do Município), de três vasos de guerra fundeados no Tejo (Adamastor, São Rafael e, posteriormente, o cruzador Dom Carlos, navio almirante), de duas unidades do Exército (Infantaria 16 em Campo de Ourique e Artilharia 1 em Campolide) e na acção de milhares de civis das "choças" carbonárias indispensáveis ao controlo da cidade de Lisboa, sabotando as comunicações dos comandos monárquicos, cortando acessos por estradas e caminhos-de-ferro, emboscando as tropas fiéis nas ruas.

Os acontecimentos revolucionários concentraram-se, assim, em três teatros principais. Na Rotunda, onde, após vários confrontos com a Guarda Municipal, os revoltosos se barricaram na madrugada de 4 de outubro, a que, sob o fogo de Artilharia 1 e das cargas da Guarda Municipal, se foram juntando milhares de civis e de militares desertores sob o comando do membro da Alta Venda da Cabonária, o comissário naval Machado Santos.

Os revoltosos resistiram às tropas fiéis à monarquia, comandadas a partir do Quartel do Carmo, onde, no dia 5 de manhã, Machado Santos se dirigiu para aceitar a rendição do Alto-Comando monárquico. 0 segundo teatro foi o da linha do Tejo, em articulação com 0 Quartel de Marinheiros, e mais tarde com o Arsenal de Marinha. Não tendo conseguido, no dia 4, ocupar o Palácio das Necessidades, os revoltosos, com o apoio da artilharia civil da 
carbonária nas ruas do bairro, combateram as forças militares fiéis à monarquia até que os navios Adamastor e São Rafael bombardearam o Palácio Real das Necessidades, pondo em fuga a família real, primeiro para Mafra, depois, no dia 5 de outubro, com destino a Gibraltar, embarcando na praia da Ericeira. Por fim, a rua, desde Alcântara até a zona oriental de Lisboa, onde os grupos carbonários combateram as forças monárquicas. Apesar de alguma resistência e dos vários confrontos militares, o exército fiel à Monarquia não conseguiu organizar-se de modo a derrotar os revoltosos.

A Revolução saiu vitoriosa. Na manhã do dia 5 de outubro de 1910 foi proclamada a República em Portugal, a segunda na Europa, e anunciado o Governo Provisório da varanda da Câmara Municipal de Lisboa pela voz de José Relvas. ${ }^{44}$

Monarca e família real chegaram a Gibraltar a bordo do iate Amélia, a 7 de outubro de 1910. Daí partiriam para o exílio, em Londres.

A praça do município encheu-se, saudando, de forma expectante, a vitória dos republicanos. Por entre aplausos, coube a Eusébio Leão ler o texto que proclamava o novo regime, anunciando, em seguida, a constituição do primeiro Governo Provisório: Presidente, Teófilo Braga; Interior, António José de Almeida; Justiça, Afonso Costa; Finanças, Basílio Teles; Guerra, Correia Barreto; Marinha, Amaro de Azevedo Gomes; Obras Públicas, António Luís Gomes, e Estrangeiros, Bernardino Machado.

A notícia do sucesso da Revolução espalhou-se rapidamente pelas localidades mais próximas de Lisboa (Santarém, Portalegre, Évora e Setúbal); recorde-se que a República já tinha sido proclamado na véspera, em Loures e em vários municípios da margem sul do Tejo.

Numa manifestação evidente de reconhecimento aos jornais que estiveram mais diretamente envolvidos na implantação da República o município lisboeta atribuiu, a 18 de novembro de 1910, nomes de jornais a três ruas da cidade: rua do Mundo, atribuído à rua de S. Roque; rua da Lucta, atribuído à rua Duque de Bragança, e rua do Século, atribuído à rua Formosa.

A 22 de outubro de 1910 a República portuguesa era reconhecida pelo Brasil, um dos primeiros países, juntamente com a Argentina, a reconhecer o novo regime.

\section{ConClusões}

A poiado num quadro de valores ideológicos herdado da Revolução Francesa e fortetuguês, cujas bases foram lançadas a 25 de março de 1876 preparou ao longo de mais de duas décadas o derrube da monarquia. Os republicanos criticaram os excessos da Casa Real, 
condenaram a situação financeira interna e o excesso de poder da igreja católica, defendendo o progresso económico e social e a construção de um sistema de ensino prático e utilitário.

A 5 de outubro de 1910 Portugal era um país caracterizado por uma indústria insipiente, dispersa e apoiada numa mão-de-obra pouco qualificada; era detentor de uma agricultura pouco intensiva, alicerçada em práticas rotineiras e rudimentares, incapaz de satisfazer as necessidades básicas do consumo da população. A implantação da República acabou por não representar, no imediato, mudanças significativas na estrutura económica e social portuguesa. O Governo Provisório continuou, de resto, a aplicar o modelo económico dos últimos anos da monarquia, que tão duramente tinha criticado, mostrando-se incapaz de combater o descontentamento crescente do operariado.

A primeira reunião formal do Conselho de Ministros foi realizada no Ministério da Guerra, na madrugada do dia 9 de outubro, e o essencial da discussão centrou-se em torno da necessidade de enquadrar/resolver a questão religiosa. Do encontro saiu o decreto da autoria do ministro da Justiça, Afonso Costa, ordenando a expulsão ou a passagem compulsiva dos membros de ordens religiosas à vida secular. A reação à atuação do ministro da Justiça não tardou e as primeiras críticas surgiram logo no interior do próprio Governo. António José de Almeida apressou-se a expedir uma circular aos governadores civis recomendando que o culto religioso fosse respeitado em todas as igrejas, condenando a proibição de manifestações que Ihe fossem contrárias, dando visibilidade às primeiras divisões internas.

A 14 de março de 1911 era publicada a primeira lei eleitoral da República. Embora previsse um alargamento substancial do sufrágio, o diploma acabou por ficar bastante aquém do que o PRP tinha prometido durante o tempo da propaganda (Almeida, 1998); as bases dos principais artigos do diploma, que não iam além da concessão do direito de voto aos indivíduos do sexo masculino - com mais de 21 anos - que soubessem ler e escrever, e aos chefes de família, deixavam antever, de forma bastante tímida, a possibilidade de algumas poucas mulheres exercerem o direito de voto. ${ }^{45}$ De resto, e quanto ao essencial, apenas $14,2 \%$ da população continuava a poder votar; o sufrágio continuava a ser restrito, e não universal, como inicialmente se pensaria (Bernardo, 2002). Quando a I Guerra Mundial teve início, no verão de 1914, eram vários os sectores da população portuguesa a quem continuava a ser negado o direito de participação política, o que, por si só, provocou um descontentamento crescente e um mal-estar generalizado no seio da República.

À luz da tese que fundamenta a intervenção de Portugal na Grande Guerra, em março de 1916, na necessidade da República se defender internamente só a intervenção no teatro de guerra europeu podia dissipar clivagens e atenuar fracturas, colocando um ponto final à instabilidade política que tinha caracterizado os primeiros quatro anos do regime (recorde-se que 
durante esse curto espaço de tempo foram nomeados sete governos), no entanto a verdade é que esta opção política esteve longe de conseguir unir o País em torno da mobilização para a Guerra, acabando por ser uma das principais causas da queda do regime.

A 28 de maio de 1926 a breve experiência republicana chegava ao fim em Portugal, interrompida pelo golpe militar comandado por Gomes da Costa, golpe a que em 1933 sucederia o Estado Novo, de António de Oliveira Salazar.

\section{NOTAS}

$1 \mathrm{Cf}$. http://centenariorepublica.pt.

2 Ver em particular Silva, Carneiro e Salmi (2011).

3 No final da República encontravam-se cerca de 1 milhão de emigrantes portugueses no Brasil. Anualmente enviavam para Portugal cerca de 20.000 contos-ouro.

4 Acontecimento que a imprensa evocou e destacou. Ver, entre outros, "Foi proclamada a República no Brasil. 0 povo brasileiro, esse povo nosso irmão pela raça, pelo idioma, pelas tradições e pelo temperamento, acaba de dar ao mundo um grande exemplo e de praticar um acto nobilíssimo de patriotismo e de justiça. Siga Portugal o seu exemplo." Os Debates, 16 de novembro de 1889, p.1.

5 José Maria Latino Coelho (1825-1891) nasceu em Lisboa. Militar formado pela Escola do Exército, em 1851 foi nomeado lente substituto da cadeira de Mineralogia e Geologia da Escola Politécnica de Lisboa. Colaborador dos jornais Revolução de Setembro (1849) e A Semana, dirigiu o Diário de Lisboa (1859), então jornal oficial do Governo. Foi eleito deputado pela primeira vez a 3 de dezembro de 1854, integrando as listas do Partido Regenerador. Fundou o Clube dos Lunáticos, de que eram membros: António de Oliveira Marreca, Elias Garcia e Augusto Saraiva de Carvalho, e esteve envolvido na organização do Centro Republicano de Lisboa.

6 O Século, 16 de novembro de 1889, p.1.

7 Veja-se em particular: Os Debates, 18 de novembro de 1889, e O Século, 21 de dezembro de 1889, p.1.

8 António José de Almeida (1866-1929), médico republicano nascido em Penacova, fez parte de um grupo de estudantes que após o Ultimato britânico de 1890 agitou o País com uma campanha propagandística intensa contra o Governo. Partiu para S. Tomé em 1896, onde exerceu medicina, regressando sete anos mais tarde ao território continental.Foi ministro do interior do Governo Provisório, presidente do Ministério e ministro das Colónias durante o Governo de União Sagrada (15 de março de 1916 a 25 de abril de 1917). A 6 de agosto de 1919 foi eleito Presidente da República, cargo que exerceu durante quatro anos, tornando-se o único Chefe de Estado a cumprir, na íntegra, o seu mandato durante a I República.

9 O Século, 30 de junho de 1890, p.1.

10 Domingos Higino da Ponte e Sousa (1862-1904), oftalmologista, professor da Escola Médico-Cirúrgica de Lisboa e médico assistente do Hospital de São José.

11 Manuel de Brito Camacho (1862-1934), médico formado pela Escola Médico-Cirúrgica de Lisboa, fundou em 1906 o jornal republicano $A$ Lucta. Desempenhou as funções de ministro do Fomento (22 de novembro de 1910 a 3 de setembro de 1911), constituindo em 1912, a partir da cisão do Partido Republicano, a União 
Republicana, de que foi líder. Alto-comissário da República em Moçambique entre 1920 e 1923, a sua acção pautou-se pelo desenvolvimento e pela descentralização.

12 Programa do Partido Republicano Portuguez, Lisboa, A Liberal, Oficina Tipográfica, 1908.

13 João Pinheiro Chagas (1863-1925), jornalista nascido no Rio de Janeiro, começou a trabalhar no Porto, na redação do Primeiro de Janeiro. Fundou o jornal República Portuguesa, órgão que utilizou para criticar a Monarquia na sequência do Ultimato britânico de 1890. Foi considerado um dos principais impulsionadores da revolta republicana do Porto de 31 de janeiro de 1891, tendo sido julgado em Conselho de Guerra e deportado para Angola, de onde acabou por fugir para Paris.

14 O Mundo, 30 de janeiro de 1910.

15 A Carbonária Portuguesa teve a sua origem na Maçonaria Académica fundada em 1897 por estudantes pertencentes ao Grémio Democrático Académico.

16 Decreto de 31 de janeiro de 1908, estabelecendo várias providências para a repressão dos crimes previstos no artigo 1을 do decreto de 21 de novembro de 1907. Diário do Governo, no 25, de 1 de fevereiro de 1908. No início do mês, António José de Almeida tinha publicado um artigo intitulado: "Republicanos" no jornal $A$ Vanguarda. Veja-se A Vanguarda, 3 de janeiro de 1908, p.1.

17 Em 1906 Brito Camacho tinha já posto em relevo algumas considerações em torno do conceito de revolução que defendia: "A revolução que urge fazer, a grande, a fecunda, a redentora revolução, não pode ser feita pelas tropas; hão-de fazê-la os evangelizadores de princípios, os semeadores de ideias, os apóstolos do bem e da verdade, do direito e da justiça. E só quando eles tiverem realizado a sua obra eminentemente revolucionária e eminentemente pacífica; quando eles tiverem espalhado a luz a jorros; iluminando as inteligências, e tiverem apostolado pelo exemplo das mais altas virtudes contra todos os crimes e vícios, só então soará o momento da outra revolução, e para a fazer não será necessária a audácia de um herói, bastará a firme decisão de meia dúzia de indivíduos".

18 Veja-se o enfoque que foi dado ao regicídio nas primeiras páginas da imprensa internacional: "Assassinat du Roi de Portugal et du Prince Héritier" in Le Petit Journal, 2 février 1908, p.1.; "La tragédie de Lisbonne. Comment le Roi de Portugal et le Prince héritier ont été assassinés" in Le Petit Journal, 3 février 1908, p.1, e "King Carlos and Heir Slain. Portuguese Sovereign and Crown Prince shot in street at Lisbon" in New York Tribune, February $2^{\text {nd }} 1908$, p. 1 . Ver, entre outros aspectos, também, a notícia de luto nacional decretada pela aliada Grã-Bretanha: "Lord Chamberlain's office, St. James Palace, February 3, 1908. The King Commands that the Court shall wear mourning for four weeks for this day, for His late Majesty the King of Portugal and the Algarves, K.G. and His late Royal Highness the Crown Prince of Portugal", The London Gazette, February 3, 1908, p.1.

19 Sobre as eleições municipais ver também: "En Portugal" in Le Petit Journal, 2 novembre 1908, p.3. Na sequência do ato eleitoral o ministro da Guerra castigou Tomás Cabreira, que tinha integrado a lista do PRP, com uma pena de seis meses de inatividade temporária. A questão foi abordada por Brito Camacho em aviso prévio dirigido ao ministro da Guerra. Cf. Diário da Câmara dos Senhores Deputados, Sessão no 54, 30 de agosto de 1909, p.3-4.

20 Foram eleitos vereadores por Lisboa: José Veríssimo de Almeida, José Belo, Manuel António Dias Ferreira, Anselmo Braamcamp Freire, José Miranda do Vale, Carlos Victor Ferreira Alves, José Soares da Cunha e Costa, Francisco Almeida Grandela, Augusto José Vieira, Tomé de Barros Queiroz, José Soares da Cunha, Miguel 
Ventura Terra, António Cardoso de Oliveira, Tomás Cabreira, Luís Filipe da Mata, Agostinho José Fontes, António Aurélio da Costa Ferreira, António Alberto Marques e José Mendes Neves Loureiro.

21 A missão foi recebida na capital britânica pelo subsecretário Parlamentar dos Negócios Estrangeiros, Thomas Mackinnon Wood, tendo contado com o apoio dos jornais Times e Economist. David Lloyd George, com quem também se encontraram, colocou igualmente à disposição dos republicanos portugueses as páginas do jornal The Nation.

22 Ver a opinião de António José de Almeida em "Diplomacia republicana" in Alma Nacional, no 23, de 14 de julho de 1910, p.365.

23 ldem.

24 ldem.

25 Idem, p.366.

26 Sobre o debate no Parlamento em torno desta questão, veja-se: Diário da Câmara dos Senhores Deputados, Sessão no 24 de 19 de abril de 1910, p. 6-7; Diário da Câmara dos Senhores Deputados, Sessão no 25, de 22 de abril de 1910, pp.1-14.

27 António José de Almeida, "Miseráveis!" in Alma Nacional no 7, de 24 de março de 1910, p.109, e "Cínicos" in Alma Nacional no 10, de 14 de abril de 1910, pp.156-158.

28 António José de Almeida, "Dilema" in Alma Nacional no 11, de 21 de abril de 1910, p.174.

29 António José de Almeida, "Expiação" in Alma Nacional no 14, de 12 de maio de 1910, p.220.

30 António José de Almeida, "São horas" in Alma Naciona, no 20, de 23 de junho de 1910, p.318.

31 Idem.

32 ldem.

33 António Maria de Azevedo Machado Santos (1875-1921) nasceu em Lisboa a 10 de janeiro de 1875 e entrou para a Marinha em 29 de outubro de 1891.

34 Idem, p.397.

350 PRP conseguiu eleger deputados em três círculos eleitorais: Lisboa - Afonso Costa, António José de Almeida, João de Meneses, Alexandre Braga, Bernardino Machado, Miguel Bombarda, António Luís Gomes, Alfredo Magalhães, Cândido dos Reis e Teófilo Braga; Setúbal - Fernandes Costa, Feio Terenas e Aurélio da Costa Ferreira; Beja - Manuel de Brito Camacho. Cf. A República triunfa! in A Capital, 28 de agosto de 1910, p.1.

36 "Está aberta a sessão! Cá fora: muito rigor policial. Lá dentro: nenhum entusiasmo" in A Capital, 23 de setembro de 1910, pp.1-2.

37 António José de Almeida, "Entendido!" in Alma Nacional no 33, de 22 de setembro de 1910, p.542.

38 Miguel Augusto Bombarda (1851-1910), médico especialista em doenças neurológicas, especializou-se em Psiquiatria e desenvolveu uma atividade académica intensa tanto a nível nacional como internacional. Eleito deputado em 1908, membro do Partido Republicano, foi assassinado por um paciente na véspera da implantação da República, a 4 de outubro de 1910. Veja-se nomeadamente "A reação...uma influência 
malévola arma o braço de um louco. 0 Dr. Bombarda ferido gravemente por um desequilibrado" in A Capital, 3 de outubro de 1910, pp.1-2.

39 Sobre os últimos momentos da vida de Miguel Bombarda ver, entre outros, Pereira e Pita, coord. (2006). Cf. igualmente As Constituintes de 1911 (1911: 238) e Camacho (1920: 113).

40 "Morte do Dr. Miguel Bombarda. 0 ilustre professor da Escola Médica e deputado republicano por Lisboa foi ontem assassinado. Até ao último momento íntegro cidadão fala aos seus amigos na pátria, que sempre Ihe foi querida, e na sua libertação pela República" in A Lucta, 4 de outubro de 1910, p.1.

41 Mira e Ribeiro (s/d: 63). "Tropas na rua o que há?" in A Lucta, 4 de outubro de 1910, p.2.

42 Cf. Diário da Câmara dos Deputados, 29a Sessão Ordinária de 22 de janeiro de 1914, p.28-29.

43 Sobre as movimentações de tropas durante a revolução cf. nomeadamente Proclamação da República Portugueza... (s/d) e Machado Santos (1982: 70 e seguintes).

44 "Viva a República!" in A Capital, 5 de outubro de 1910, p.1. Vale a pena ver a mensagem do novo Governador Civil, Eusébio Leão, dirigida à população de Lisboa: "Ordem e trabalho é a divisa da Pátria libertada pela República. A todos os cidadãos de Lisboa se pede que sejam os primeiros a manter a tranquilidade pública. Respeito pelas pessoas e propriedades dos estrangeiros, respeito pelas pessoas e propriedades dos portugueses sejam quais forem as suas classes, profissões e opiniões políticas ou religiosas" ("A República Portuguesa. Pátria e Liberdade. Governo Civil de Lisboa ao Povo" in A Capital, 5 de outubro de 1910, p.1).

45 "Os principais tópicos da nova lei eleitoral" in A Capital, 14 de março de 1911, p.1. Decreto com força de lei de 14 de março, Diário do Governo no 60, de 15 de março de 1911.

\title{
REFERÊNCIAS BIBLIOGRÁFICAS
}

\section{PublicaÇÕes PERIÓdicas, BOLETINS, JORNAIS E REVISTAS}

\author{
A Capital \\ A Vanguarda \\ Alma Nacional \\ Le Petit Journal \\ New York Tribune \\ The London Gazette
}

\section{DoCUMENTAÇÃo dos ÓRGÃos DE SOBERANiA}

As Constituintes de 1911 e os seus Deputados. Obra compilada e dirigida por um antigo oficial da secretaria do Parlamento. Lisboa: Livraria Ferreira, 1911.

Constituição Política da República Portuguesa de 21 de Agosto de 1911. Coimbra: F. França Amado, 1911. 
Diário da Câmara dos Senhores Deputados

Diário do Governo

Discursos dos ilustres deputados republicanos Srs. Drs. Afonso da Costa, Alexandre Braga, António José de Almeida e João de Menezes. Lisboa: Tipografia Pereira Vendinha, 1906.

\section{BiBLIOGRAFIA}

ALMEIDA, José Luís de. Memórias do Sexto Marquês do Lavradio. Lisboa: Editora Nova Ática, 2004.

ALMEIDA, Pedro Tavares de. Legislação eleitoral portuguesa (1820-1926). Lisboa: Imprensa Nacional-Casa da Moeda, 1998.

António José de Almeida, Quarenta anos de vida literária e política. 4 vols. Lisboa: J. Rodrigues \& Cia., 1933.

BARBOSA, Luísa Maria Gonçalves Teixeira. O ideário republicano nas relações Brasil/Portugal 1880-1891. Dissertação de Mestrado em História e Cultura do Brasil, Faculdade de Letras da Universidade de Lisboa, 2002 (Policopiado).

BERNARDO, Maria Ana. A dinâmica dos recenseamentos eleitorais no final da Monarquia e na I República. Uma reflexão em torno de duas variáveis: alfabetizados e emigrantes, Penélope. Revista de História e Ciências Sociais, no 27, 2002, p.93-124.

BRAGA, Teófilo. História das ideias republicanas em Portugal. Lisboa: Veja, 1983.

CABRAL, António. Cartas d'El Rei D. Manuel II. Lisboa: Livraria Popular de Francisco Franco, 1933.

CAMACHO, Brito. Nas horas calmas. Lisboa: Guimarães \& Cia., 1920.

CATROGA, Fernando. O republicanismo em Portugal da formação ao 5 de outubro de 1910. 2 vols. Coimbra: Faculdade de Letras, 1991.

CHAGAS, João. Subsídios para a história da ditadura. Lisboa: Tipografia do Anuário Comercial, 1908.

\& COELHO, Ex. Tenente. História da Revolta do Porto de 31 de janeiro de 1891 (Depoimento de dois cumplíces). Lisboa: Empresa Democrática de Portugal, s/d.

Da Monarchia à Republica. Relato do movimento que originou a implantação da República em Portugal. Pref. Magalhães Lima. Lisboa: Empreza de Publicações Populares, 1910.

Dr. António José de Almeida, Galeria Republicana I, Biblioteca Democrática. Lisboa: Tipografia Bayard, 1906.

FERREIRA, David. História política da Primeira República Portuguesa (1910-1915). I Parte, Lisboa: Livros Horizonte, 1973.

1973.

História política da Primeira República Portuguesa (1910-1915). II Parte, Lisboa: Livros Horizonte,

GOMES, Manuel Teixeira. Correspondência I. Cartas para políticos e diplomatas. Lisboa: Portugália Editora, 1960. 
—_. Correspondência II. Cartas para políticos e diplomatas. Lisboa: Portugália Editora, 1960.

KURZMAN, Charles. Democracy denied 1905-1915. Intelectuals and the fate of democracy. United States of America, Harvard University Press, 2008.

LAINS, Pedro. Os progressos do atraso. Uma nova História Económica de Portugal (1842-1992). Lisboa: Imprensa de Ciências Sociais, junho de 2003.

LEAL, Cunha. Coisas de tempos idos. As minhas memórias. Romance duma época, duma família e duma vida de 1888 a 1917. Lisboa: Edição do Autor, 1966.

LEAL, Ernesto Castro. Partidos e programas. O campo partidário republicano português (1910-1926). Coimbra: Imprensa da Universidade de Coimbra, julho de 2008.

—. Manifestos, estatutos e programas republicanos portugueses (1873-1926). Antologia. Lisboa: Imprensa Nacional-Casa da Moeda: 2014.

LIMA, Sebastião de Magalhães. Da Monarchia à Republica. Relato do movimento que originou a implantação da República em Portugal. Lisboa: Empreza de Publicações Populares, s/d.

MACHADO, Bernardino. Pela República 1906-1908. Lisboa: Edição de Autor, 1908.

MAGALHÃES, Joaquim Romero. Vem aí a República! 1906-1910. Lisboa: Almedina, 2009.

MIRA, Ferreira de \& RIBEIRO, Aquilino. Brito Camacho. Lisboa: Livraria Bertrand, s/d.

MÓNICA, Maria Filomena. O Senhor Ávila e as Conferências do Casino. Análise Social, Lisboa, vol. XXXV, no 157, 2001, p.1013-1014.

PABON y SUÁREZ de URBINA, Jesús. La Revolución Portuguesa: (de Don Carlos a Sidonio Pais). Madrid: Espasa-Calpe, 1941.

PEREIRA, Ana Leonor \& PITA, João Rui (coords.). Miguel Bombarda (1851-1910) e singularidades de uma época. Coimbra: Imprensa da Universidade de Coimbra, 2006.

PINHEIRO, Maria Namorado \& SOUSA, Alexandre. Legislação eleitoral portuguesa: textos históricos (18201974), Tomo II. Lisboa: Comissão Nacional de Eleições, 1998, pp.511-613.

PIRES, Ana Paula. António José de Almeida. O Tribuno da República. Lisboa: Assembleia da República - Divisão de Edições, junho de 2011.

_ e ROLLO, Maria Fernanda. Manuel de Brito Camacho um intelectual no Parlamento. Lisboa: Assembleia da República - Divisão de Edições, 2015.

Proclamação da República Portugueza. Programma do Partido Republicano e História completa da Revolução. Lisboa: Tipografia Comércio e Indústria, s/d.

PROENÇA, Maria Cândida. D. Manuel II. Lisboa: Círculo de Leitores, janeiro-fevereiro de 2006.

Programa do Partido Republicano Portuguez. Lisboa: A Liberal, Oficina Tipográfica, 1908.

QUENTAL, Antero de. Causas da decadência dos povos peninsulares. Lisboa: Ulmeiro, 1994.

REIS, Carlos. As conferências do Casino. Lisboa: Publicações Alfa, 1990. 
RELVAS, José. Memórias políticas. Lisboa: Terra Livre, 1977.

ROLLO, Maria Fernanda. Engenharia e História: percursos cruzados. In: BRITO, José Maria Brandão de, HEITOR, Manuel \& ROLLO, Maria Fernanda (coords.). Engenho e obra - uma abordagem à história da engenharia em Portugal do século XX. Lisboa: Publicações Dom Quixote, 2003.

ROSAS, Fernando \& ROLLO, Maria Fernanda (coords.). História da Primeira República Portuguesa. Lisboa: Tinta da China, 2009.

SALGUEIRO, Ângela Sofia Garcia. Ciência e universidade na I República. Tese de doutoramento em História Contemporânea apresentada à Faculdade de Ciências Sociais e Humanas da Universidade Nova de Lisboa. Lisboa: julho de 2015.

SAMARA, Maria Alice. 0 republicanismo. In: ROSAS, Fernando \& ROLLO, Maria Fernanda (coord.). História da Primeira República Portuguesa. Lisboa: Tinta da China, 2009.

- As Repúblicas da República. História, cultura política e republicanismo. Dissertação de Doutoramento em História Contemporânea, Institucional e Política de Portugal apresentada à Faculdade de Ciências Sociais e Humanas da Universidade Nova de Lisboa em 2010.

SANTOS, Fernando Piteira. Raul Proença e a alma nacional. Lisboa: Publicações Europa-América, 1979.

SANTOS, Machado. A Revolução Portuguesa 1907-1910 (prefácio de Joel Serrão). Lisboa: Assírio e Alvim, janeiro de 1982.

SILVA, António Maria da. O meu depoimento. Da Monarquia a 5 de Outubro de 1910. Vol I, s/l, s/e, s/d.

SILVA, Armando Malheiro da, CARNEIRO, Maria Luiza Tucci \& SALMI, Stefano (coords.). República, republicanismo e republicanos. Brasil (1889), Portugal (1910) e Itália (1945). Para uma leitura comparada. Coimbra: Imprensa da Universidade de Coimbra, outubro de 2011.

SILVA, Isabel Corrêa da. O espelho fraterno. Lisboa: Divina Comédia, 2013.

SOUSA, António Teixeira de. Para a História da Revolução. Vol. I. Porto: Tipografia da Empresa Litográfica e Tipográfica, 1912.

SOUSA, Bernardo Vasconcelos, RAMOS, Rui \& MONTEIRO, Nuno Gonçalo. História de Portugal. Lisboa: Esfera dos Livros, 2012.

TORGAL, Luís Reis \& RAMIRES, Alexandre, António José de Almeida, Lisboa: Museu da Presidência da República, janeiro de 2006. 